\title{
How to appoint a senior house officer
}

One of the first jobs a newly appointed consultant may need to do is to appoint one or more senior house officers (SHOs). Appointments in medicine are a two stage procedure. The curriculum vitae (CV) is used to shortlist candidates, and the final decision on appointment is made at interview, taking into account CVs and references. It is worth remembering that there are other means of assessment such as personality testing or practical testing of skills which are used in other professions, and it is possible that the way we appoint doctors at all grades could be improved. The medical staffing department will advertise the post, acknowledge applications, obtain references and so on, but the choice of candidate is made by the accident and emergency (A\&E) consultant. This article describes how one person approaches the subject.

Before appointing any member of staff it is important to ask oneself these questions:

- Can they do the job? (that is, do they have the ability and are they physically fit enough to do the job?)

- Will they do the job? (that is, do they have the motivation to do the job?)

- Are they compatible? (that is, with consultants, other junior staff, nursing staff, patients.)

If one cannot answer yes to all three of these questions, it is unwise to appoint, even if there is only one applicant.

Usually there will be more applicants than posts and it is necessary to make a choice. In appointing a person for a service role, the aim is of course to select the person who will do the job best. This will usually (but not always) be the best qualified and most experienced candidate. However, SHOs are in training posts and, for the sake of both post and candidate, one should only appoint a person who will benefit from that training.

Although it is useful to have experienced staff working in the department, a person applying for a second job in A\&E should be quizzed carefully about their career plans and, if appointed, plans should be made for them to gain additional training by, for example, attending courses or doing a research project. It should be exceptional to appoint a person with more than 12 months $A \& E$ experience to an SHO post in the specialty.

It is sometimes thought that appointments are a lottery or even a game, but they should not be. The theoretical basis to selection is that personality does not change and that the best predictor of a person's future performance is not what they say they will do but their past performance. A doctor, qualified 18 months, who already has the first part of a higher qualification and certification in ATLS and ALS has more "drive" and is likely to achieve more than an equally able person without these qualifications. The person who upsets the nursing staff in both medical and surgical house officer posts will probably do the same in $\mathrm{A} \& \mathrm{E}$.
If $A \& E$ is included in a surgical or general practice (GP) training scheme, one may need to consider candidates not only as potential doctors working in A\&E but also with regard to their career aspirations and other jobs in the training scheme. In large training schemes with many options not all specialties may be represented on an appointments committee. For example if, when appointing to a GP training scheme, there is no paediatrician on the committee, it may be necessary to safeguard the interests of the paediatric department (which may be different from those of $A \& E$ ), as well as choosing the best candidate for a career in general practice.

\section{Person specification}

It should go without saying that one must not breach equal opportunities and race relations legislation but, further than that, all appointments must be made fairly and must be seen to be made fairly. All substantive posts must be advertised and a proper interview held. Nobody must be "promised" a job in advance. Rejected candidates have the right to complain about the findings of an appointments committee and so one must be able to justify decisions. The best way to do this is to write down the qualifications, knowledge, experience, and qualities which are necessary to do the job and to judge applicants against those alone. This is the person specification. Different people will have different ideas as to what constitutes an ideal A\&E SHO, but my own thoughts on a person specification for an $A \& E$ SHO are shown in table 1 and are described below.

\section{QUALIFICATIONS}

It is essential that $A \& E$ doctors are qualified and on the medical register. Particular care must be taken when appointing foreign graduates who are not currently working in the country, to ensure they can obtain registration before the start of the job. The medical staffing department will advise.

Certification in ATLS/ALS/APLS/PALS etc, indicates training in specific aspects of $A \& E$ work and is an obvious bonus.

The possession of the first part of a higher qualification or medical school prizes is an indication of application to a task and so is welcome. Honours in final exams indicates intelligence, which will be of benefit if combined with ability and enthusiasm.

\section{KNOWLEDGE}

In $A \& E$, which is commonly chosen as a first postregistration job, we accept that most junior staff arrive with no knowledge of the specialty. However, significant A\&E experience gained as a student or some experience in orthopaedics is clearly a bonus.

\section{EXPERIENCE}

While previous knowledge of $A \& E$ is not essential, it is important to have certain basic skills. All British graduates 
Table 1 Person specification for an SHO post in $A \mathcal{E} E$

\begin{tabular}{llll}
\hline & Essential & Desirable & Bonus \\
\hline $\begin{array}{l}\text { Qualifications } \\
\text { Knowledge }\end{array}$ & Registered & & ATLS/ALS, etc; part 1 exams; prizes \\
$\begin{array}{l}\text { Experience } \\
\begin{array}{l}\text { Personal experience } \\
\text { Other requirements }\end{array}\end{array}$ & $\begin{array}{l}\text { HP \& HS or equivalent } \\
\text { Ability to communicate }\end{array}$ & $\begin{array}{l}\text { 1 or 2 SHO jobs; worked in UK } \\
\text { Enthusiasm }\end{array}$ & \multirow{2}{*}{ Expressed prior interest in job }
\end{tabular}

applying for an SHO post will have done house officer jobs in medicine and surgery and I believe that all A\&E SHOs should have equivalent experience. A\&E covers such a wide range of problems that it is essential to be able to assume that SHOs have learned the basic skills of assessing medical and surgical patients so one can concentrate early teaching on trauma and paediatrics. However, the experience gained in house officer posts varies considerably and it is important to find out what was actually learned during the year. The house surgeon who saw patients with abdominal pain and tried to establish a diagnosis before they were reviewed by a more experienced doctor and then attended theatre, doing the occasional minor operation and closing surgical wounds, will bring more experience to the post than the house surgeon who simply clerked elective patients on a very specialised firm and left the initial assessment of acute admissions to the SHO. Similarly the house physician from a hospital where patients with chest pain are admitted by the "on-take" firm rather than by a cardiology SHO should be more confident than the doctor without that experience. This general experience should be recent. A doctor who has done nothing but, say, family planning for 10 years, is likely to be out of date on acute medicine and is likely to need some kind of refresher training before spending a night on-call in $A \& E$. Experience in suturing, wherever gained, is useful.

$\mathrm{A} \& \mathrm{E}$ is on the boundary between hospital medicine, primary care, the ambulance service, and other agencies, and unfortunately SHOs are less well supervised in most hospitals than they should be. It is of undoubted benefit for the SHO to know how the system works and to have worked previously in this country before starting work in A\&E.

SHO experience in another acute specialty is desirable. The A\&E SHO will be more competent and confident in that field and clearly has less to learn than doctors doing their first postregistration job. The department and other SHOs will also benefit from their skill and it is a rare consultant who has never learned something from an SHO. However, employing an SHO with a lot of experience may not always bring the anticipated benefits. Beware of experience obtained entirely in unsupervised posts (for example, general practice and the armed forces) as it may take longer to eradicate bad habits than to train someone from scratch. The overcautious but enthusiastic approach of an inexperienced doctor may be better than the cavalier attitude and lack of enthusiasm of some very experienced doctors still employed in an SHO grade.

\section{PERSONAL REQUIREMENTS}

An ability to communicate is absolutely essential. This is difficult to define but can be assessed at interview. Also important is enthusiasm. The enthusiastic doctor tends to work hard and get on well with other staff. Their enjoyment of the job tends to create a relaxed atmosphere in the department.

The assessment of a person's commitment starts by observing how they have applied for the job. A badly constructed $\mathrm{CV}$, with spelling mistakes, indicates a careless individual. The organised person who prepares for an interview is the kind of person who will prepare for doing the job. To apply for any job without finding out as much as possible about it and without talking to the person currently in post is unwise. It is not necessary to come before shortlisting but they should, at least, arrive an hour before the interview to look around. However, people interested enough to ask about future vacancies or to look round before the job is advertised will be given precedence, at least at shortlisting, as will doctors who are known to be enthusiastic and competent, either from contact made in other jobs within the hospital or from medical student attachments. I expect anyone making an unusual career move (for example, a principal in general practice applying for an SHO post) to explain the reason in a covering letter or by personal contact. Asking pertinent questions at the interview shows that a person has thought about the job, but to ask a question which is answered in the job description indicates lack of preparation.

Higher qualifications and courses attended have been mentioned as indicators of enthusiasm and commitment. Membership of professional societies at SHO level will indicate the same thing. The person who expresses a desire to make a career in $A \& E$ and shows evidence of this is also likely to be more committed than average. It would be unrealistic to expect more than a tiny minority of applicants for an A\&E SHO post to have any of these indicators, but one can look for evidence of enthusiasm and commitment outside medicine. Significant achievements in the sporting, musical, or voluntary work fields show evidence of a personality that will persevere to achieve a goal. If you can motivate such people, they have the ability to achieve much during a six month appointment. A\&E work is very much a team activity, and extracurricular activities may also demonstrate an ability to work with other people. Not every SHO needs to be a natural leader but it is useful to have one or two within a group of SHOs. The ability to lead or organise can be deduced from previous activities (for example, president of a student's union, organiser of the medical school summer ball). An interesting elective period may show initiative. Look out for the person who is not really interested in doing a job in $A \& E$. The usual situation is the person who has already done $A \& E$ and is now applying for a rotation which includes a second stint, or the doctor who has much experience in a surgical subspecialty who comes to the United Kingdom for training and who has to obtain an FRCS before embarking on higher training.

\section{GOOD HEALTH}

Doctors working in $\mathrm{A} \& \mathrm{E}$ have to be fit enough to work shifts. Doctors phoning at $5 \mathrm{pm}$ to say that they are unable to work the night will throw the best run department into chaos. Usually this cannot be predicted, but an applicant with a poor sickness record needs looking at carefully. If you have doubts, you may wish to appoint subject to their passing a medical examination by the occupational health service. 
Table 2 Sample list for comparing candidates

\begin{tabular}{|c|c|c|c|c|c|c|c|}
\hline Name & Age & Qualified & SHO jobs & $A T L S$ & $A L S$ & Higher quals & Notes \\
\hline Dr A & 25 & 1993 & $6 / 12 \mathrm{med}$ & - & - & Pt1 MRCP & \\
\hline Dr B & 23 & 1994 & - & - & - & - & A\&E on elective \\
\hline Dr C & 28 & 1990 & VTS & - & + & DRCOG, MRCGP & VTS didn't include $A \& E$ \\
\hline Dr D & 24 & 1994 & - & - & - & - & $3 / 12$ ortho as $\mathrm{HS}$ \\
\hline Dr E & 26 & 1992 & Ortho, paeds, A\&E & + & + & Sitting primary FRCS Jan & Wants to do $\mathrm{A} \& \mathrm{E}$ \\
\hline
\end{tabular}

\section{Shortlisting}

Given sufficient applicants, I like to shortlist four people for one vacancy, six for two vacancies, or 10 if I plan to appoint five SHOs. It is also worth having one or two reserves who can be called for interview if others withdraw. I briefly scan the CVs, rejecting anyone who does not possess the essential person specifications. The rest can be judged on how far they meet the desirable and "bonus" specifications. If there is a large number of candidates, it is useful to make a list, as in table 2, to compare them. Make brief notes on the shortlisting and keep them for three months in case there is a complaint.

\section{Interview}

The aim is not to appoint the person who performs best at interview, but the person who best matches your person specification. You already have a lot of information from the CV, and the interview is an opportunity to get more information about them and what they have done and achieved, and to compare this to your requirements. It is also an opportunity for you to "sell" your job to them.

Books have been written about interview techniques but I describe a few practical points below:

Try to make the candidates feel at ease.

The questions you ask may vary depending on the candidate's experience and CV but it is important, for fairness, that all are asked the same kind of questions. This also makes it easier to compare candidates for communication skills, ability to reason, etc.

Always ask about gaps in a CV. A six month gap probably indicates a well deserved holiday but it may indicate illness or even imprisonment.

Ask open questions. Rather than asking "Can you put in CVP lines and chest drains" you will gain much more information from questions like "What skills did you learn in your HP job?"

Ask about all previous jobs and elective periods, what conditions they treated, what they learnt and what they didn't learn-especially related to the medical problems and skills relevant to A\&E.

Although you may ask an open question, make sure that you get the information you want and don't accept vague answers. If someone says that they have an interest in audit, ask supplementary questions, for example, "Tell me about the last audit you did yourself" or "Describe an audit that has changed your practice."

Ask about career plans, what advice they have sought, and what steps they have taken to further those plans. It doesn't matter whether the candidate is a budding neurosurgeon or has no idea what they want to do and simply plan to do $A \& E$ as a means of keeping their options open: the important thing is that they have approached their career logically and with thought.

In A\&E one needs to be able to "think on one's feet," both in making diagnoses and in explaining things to patients. A half hour interview does not allow one to test clinical abilities but thinking abilities can be tested by asking a difficult and unexpected question and seeing how the candidate copes. ("If we have to introduce performance related pay for A\&E SHOs, how should we measure their performance?")

Ask applicants how they spend their free time. Their recreational interests are not important (unless they are the same as yours!), but the degree of enthusiasm with which they describe them may be very telling, and if a person cannot relax when discussing their favourite hobby or sport they never will. This question also helps you to get to know the candidate as a person. Towards the end ask "If I offer you the job today, will you be in a position to accept it?". You do not wish to offer someone a job to be told "I will take the job if I don't get the one at St XXX's tomorrow."

Make sure that all applicants understand any peculiarities of the job, even if they have been described in the job description.

Give all applicants a chance to ask you questions about the job and be prepared to answer them. Topics such as rotas and so on should be covered in the job description, and the common questions asked are details of accommodation, teaching, and the provision of study leave. They may also ask how best they can prepare for the post.

Finally, one should read the references, though they are often of little help. Very few people come with a bad reference and in those who do it is usually the result of a personality clash with one previous consultant, as evidenced by a good second reference. Personal knowledge of the referee is often very telling in this situation. More commonly one tries to read between the lines to try to decide whether comments like "... he got on well with fellow medical staff and patients" means that he fell out with nurses or whether the failure to mention nursing staff was accidental.

Make brief notes of the interview and keep them for three months. Once you have made an appointment, talk to those you didn't appoint and explain what they can do to improve their chances of appointment elsewhere. You may wish to offer some of the unsuccessful applicants a job starting at a later date and you may be aware of other vacant jobs within the hospital which they could apply for in the interviewing time.

\section{Practicalities}

Many doctors like to do $A \& E$ as their first postregistration job. The number of doctors looking for jobs is limited and, particularly for jobs not starting in early August, the posts may outnumber the people wishing to fill them. Advertise early so as to have first pick. It also means that if you do not fill the post first time you have another chance. Allow as short a time as possible (compatible with obtaining references) between advertisement and the interview date, as most applicants will apply for several jobs and will take the first one offered. To leave too long a gap risks all the shortlisted candidates taking up posts elsewhere. All jobs must be advertised in the journals but one can also advertise the job informally, for example if you are asked to lecture to house officers.

If a married couple (or equivalent) apply to work in $A \& E$ together they should be advised that this is probably unwise. They will work different shifts and may be unable 
to take annual leave together. The inevitable stress that this will put on their relationship will also have effects on the department.

One may be approached by doctors who need the opportunity to re-establish themselves in medicine. One must be practical and stay within the confines of being fair, but be prepared to give someone the break they need. At worst you will only have to put up with them for six months. You may wish to appoint them subject to conditions. For example, a doctor who had been out of clinical medicine for 18 years was appointed subject to doing clinical attachments in medicine and $A \& E$ first, and a rehabilitated alcoholic subject to remaining under supervision for his problem. Both did the job competently.

H R GULY

Accident and Emergency Department, Derriford Hospital, Plymouth

\section{Risk management}

Risk management is a tool which, in the health service, embraces management of the untoward events which have costs. The main problems and costs are legal, but risk management covers all untoward events. If a patient suffers from mistreatment, the cost is far higher than the cost of legal fees and any settlement. Even if there is no negligence, medical complications have to be treated and the investigation of complaints takes clinical and managerial time. Staff attending court have to be replaced and the hospital's reputation may suffer more than its finances.

$\mathrm{A} \& \mathrm{E}$ staff will mainly be involved in risk management in relation to negligence and other claims relating to clinical practice - clinical risk management. I dislike this term; it is negative and implies that our aim should be to avoid complaints and legal action. As clinicians, we should try to provide the best possible patient care (or the best that can be achieved with available resources) because our patients deserve nothing less, not just because we do not want to be sued. I prefer the concept of "total quality management" 2 which seeks to make continuing improvements to a system even if it is already excellent. Total quality management and risk management have different aims but the results should be similar and both should lead to improved patient care. Doctors should be involved in both.

For the practitioner, the only secret of avoiding risk is to be a good doctor: one must keep up to date but thereafter risks are created or avoided one patient at a time. ${ }^{3}$ It is essential to act professionally and build up a relationship with every patient. Do not take shortcuts in the history, examination, or record keeping. Radiographs must be interpreted with care and one should know the limits of one's competence. Finally, ensure that the patient understands the diagnosis and treatment and that one communicates properly to any other health care professional involved (for example, general practitioner, nurse).

Doctors with managerial responsibilities need a wider view. I devote most of my article to clinical risk management but clinical directors of $A \& E$ are responsible (with the help of other departments, such as occupational health and personnel) for what happens within their department and may be involved in risk management in other ways, for example:

- Non-clinical problems relating to patients (a fall from a trolley, loss of valuables..)

- Injury to visitors (slipping on a wet floor..)

- Injury to staff (back injury in nurses, needlestick injury, violence..)

- Contravention of employment legislation (unfair dismissal, sexual or racial discrimination..)

- Contravention of other legislation (health and safety, data protection..)

- Physical damage to the department (fire, theft..)
- Damage to the organisation of the department (the computer crashes with the loss of all records..)

There are four stages in risk management, as follows. ${ }^{45}$

\section{Identification of risk}

This is done by asking the question "What can go wrong?". $\mathrm{A} \& \mathrm{E}$ departments see such a wide range of problems that they are a medicolegal minefield. The answer to "what can go wrong?" is anything and everything, but the main causes for complaint and legal action are the following.

Misdiagnosis-The commonest misdiagnoses in $\mathrm{A} \& \mathrm{E}$ are injuries missed on $x$ ray but these are usually picked up by the radiologist and may not have major ill effects. Injuries missed because of failure to $x$ ray the appropriate part may take longer to come to light and have more serious consequences. Poor clinical skills lead to missing tendon, nerve, and ligamentous injuries, compartment syndrome, and so on. Non-trauma misdiagnoses such as myocardial infarction, subarachnoid haemorrhage, testicular torsion, and meningitis are less common but may have more serious repercussions.

Failure to admit-Although this may be secondary to failure to diagnose, the failure to admit may be the primary cause of complaint (for example, head injury or social problems complicating an injury). The self harm patient who is discharged and later commits suicide is another example.

Drug problems such as interactions and problems caused by failure to ask about allergies or past medical history.

Mismanagement, for example failure to manipulate a fracture, failure to recognise an inadequate reduction, incorrect treatment or failure to organise follow up. Doctors making decisions or doing procedures beyond their competence is a particular problem.

Damage to patients, for example a cut by plaster saw, leaving on a tourniquet.

In addition, there are problems which affect all doctors such as consent, anaesthesia, and minor operations. A recently described risk is that of giving telephone advice. An A\&E department must not only learn from its own mistakes but also from the mistakes of others. Keep up to date with the $A \& E$ literature on difficult diagnoses, complaints, ${ }^{6}$ and other medicolegal problems.

The question "what can go wrong?" must not be limited to errors. It is important to consider why patients complain, as only a small minority of errors result in a complaint, and many complaints are made when there has been no error. The major problem is a breakdown in communication. Patients accept that doctors are not omnipotent but they do expect them to act in a professional way and to explain things. Too often the real reason for complaint is the perception that the doctor did not care or was rude. 